\title{
Metode Background Substraction untuk Pencarian Tempat Parkir Menggunakan Kamera Pengawas
}

\author{
http://dx.doi.org/10.28932/jutisi.v6i1.2359
}

\author{
Kristian Adi Nugraha ${ }^{\bowtie} \# 1$ \\ "Informatika, Universitas Kristen Duta Wacana \\ Jl. Dr. Wahidin Sudirohusodo 5-25 Yogyakarta 55224 \\ 'adinugraha@ti.ukdw.ac.id
}

\begin{abstract}
Indonesia is a country with the high number of vehicle users. The high number of vehicles affects the needs of parking area. Meanwhile, wider parking area would make people difficult to find available parking slot. One of the solution is creating smart parking system, a system that can help people to find available parking slot easier. Most of smart parking system uses an expensive sensors installed on each parking slot to detect parked car on that slot. However, the installation of that system is too expensive, not everyone can afford it. This research purpose is to create a cheaper smart parking system using the support of CCTV's camera. The system reads the image of parking area from CCTV's camera to decide all of the captured parking slots that are available using background substraction method. The testing result shows that the accuracy of this smart parking system is 93.69\%.
\end{abstract}

Keywords- background substraction; CCTV; image processing; smart parking

\section{Pendahuluan}

Jumlah pengguna kendaraan bermotor pribadi di Indonesia berdasarkan data pada tahun 2018 mencapai kurang lebih 146 juta kendaraan [1], di mana jumlah tersebut meningkat kurang lebih sebesar 6\% dibandingkan dengan tahun sebelumnya. Bertambahnya jumlah kendaraan bermotor turut mengakibatkan dalam peningkatan akan kebutuhan area lahan parkir. Para pemilik lahan parkir harus menyediakan area yang cukup luas agar dapat menampung seluruh kendaraan yang ada. Sementara itu, apabila sebuah lahan parkir memiliki area yang luas, maka pengguna kendaraan akan semakin kesulitan dalam mencari tempat parkir yang kosong, terutama saat kondisi area parkir sedang padat. Pengguna kendaraan harus menjelajahi area parkir yang luas untuk mencari tempat parkir yang kosong agar dapat memarkirkan kendaraannya. Hal tersebut dapat menghabiskan waktu para pengguna kendaraan dalam mencari tempat parkir hanya untuk sekedar memarkirkan kendaraannya. Selain itu semakin lama kendaraan tersebut menyala maka akan menyebabkan bertambahnya polusi udara yang ada menjadi semakin pekat dan membawa dampak buruk bagi kesehatan masyarakat maupun lingkungan.

Beberapa pemilik lahan parkir mencoba mengatasi hal tersebut dengan menerapkan sistem parkir cerdas (smart parking), yaitu sebuah sistem yang mampu mempermudah pengguna kendaraan dalam mencari tempat parkir [2, 3, 4]. Umumnya sistem parkir cerdas melibatkan bantuan beberapa perangkat keras berbentuk sensor yang dapat mendeteksi ketersediaan parkir pada masing-masing slot [5]. Kemudian sensor tersebut akan memperbarui data yang disimpan pada basis data sebuah server secara berkala [6]. Pengguna kendaraan yang hendak memarkirkan kendaraan dapat melihat informasi ketersediaan tempat parkir melalui berbagai bentuk media seperti layar monitor atau perangkat ponsel cerdas (smartphone), sehingga pengguna kendaraan langsung mengetahui lokasi mana yang harus dituju tanpa mengitari area parkir [7]. Namun solusi tersebut menghabiskan biaya yang tidak sedikit jumlahnya, sehingga tidak semua pemilik lahan parkir mampu untuk mengimplementasikan sistem tersebut.

Penelitian ini mencoba untuk mengimplementasikan sebuah sistem parkir cerdas dengan biaya yang rendah dengan memanfaatkan kamera pengawas atau ClosedCircuit Television (CCTV). Sebagian besar tempat publik saat ini telah terpasang kamera pengawas untuk tujuan keamanan, termasuk di area parkir. Penelitian ini dibangun berdasarkan gagasan bahwa selain untuk keperluan keamanan, kamera tersebut dapat dimanfaatkan untuk keperluan lain, salah satunya untuk keperluan sistem parkir cerdas. Kamera tersebut dapat digunakan untuk menentukan ketersediaan slot pada sebuah area parkir berdasarkan citra hasil rekaman kamera dengan menggunakan metode background substraction. Background substraction merupakan sebuah metode yang dapat digunakan untuk melihat perbedaan dari dua buah citra, yaitu citra uji dan citra balik layar (background) [8, 9]. Mula-mula kamera pengawas harus menangkap citra saat posisi area parkir kosong seluruhnya. Citra tersebut akan dianalisis untuk mengetahui slot parkir mana saja yang terekam pada kamera tersebut, kemudian menentukan 
zona-zona yang mewakili area sebuah slot tempat parkir. Langkah berikutnya adalah sistem membaca citra dari kamera pengawas secara berkala, misalnya setiap satu menit sekali. Kemudian sistem membandingkan citra yang baru dengan citra pertama saat kondisi lahan parkir sedang kosong menggunakan metode background substraction. Apabila terdapat perbedaan pada satu atau beberapa zona yang telah ditentukan, maka slot parkir pada zona tersebut sedang terisi. Namun sebaliknya jika citra pada zona tersebut masih sama dengan citra awal, maka zona tersebut masih kosong. Informasi tersebut akan disimpan ke dalam basis data, kemudian pengguna kendaraan dapat mengakses basis data tersebut melalui aplikasi smartphone. Pada penelitian ini terdapat batasan dari objek penelitian yang akan diteliti yaitu hanya kendaraan bermotor roda empat atau mobil, dengan pertimbangan hanya kendaraan beroda empat yang memiliki batas parkir yang jelas menggunakan garis pembatas untuk tiap kendaraan pada area parkir. Metode ini diharapkan dapat dimanfaatkan untuk membangun sebuah sistem parkir cerdas yang tidak memakan banyak biaya namun tetap dapat memberikan hasil yang baik, sehingga pihak-pihak yang memiliki anggaran terbatas tetap dapat membangun sebuah sistem parkir cerdas.

\section{TINJAUAN PUSTAKA}

Sistem parkir cerdas (smart parking system) merupakan salah satu solusi yang bertujuan untuk menangani banyaknya jumlah pengguna kendaraan yang hendak memarkirkan kendaraannya, agar proses tersebut dapat dilakukan dengan mudah dan cepat $[10,11]$. Fitur yang harus tersedia dalam sistem parkir cerdas adalah bagaimana sistem tersebut dapat mendeteksi kosong atau tidaknya sebuah area parkir secara akurat. Pada umumnya, sistem parkir cerdas menggunakan bantuan alat berupa sensor untuk mendeteksi kosong atau tidaknya sebuah area parkir [11]. Setiap sensor terhubung ke sebuah perangkat mikrokontroler yang dapat mengirimkan informasi secara berkala kepada server pusat, di mana teknologi ini dikenal dengan nama Internet of Things $[13,14]$.

Perangkat sensor dapat digunakan untuk mendeteksi ketersediaan area parkir secara akurat, namun membutuhkan biaya yang cukup besar untuk instalasinya. Terdapat sistem parkir cerdas dengan pendekatan lain yang memanfaatkan kamera dipadukan dengan metode pengolahan citra digital. Jaya, Sarabreet, Naveen, dan Uma melakukan sebuah simulasi sistem parkir cerdas dengan menggunakan diorama tempat parkir [15]. Setiap slot parkir diberi cat berwarna hijau sebagai penanda. Apabila terdapat mobil yang sedang parkir, maka penanda tersebut tidak akan tertangkap oleh kamera. Kemudian penelitian tersebut diimplementasikan secara nyata oleh Al-Kharusi dan Al-Bahadly [16]. Di setiap lantai slot area parkir dipasang sebuah kertas berbentuk lingkaran berwarna hijau. Apabila kamera berhasil menangkap citra berisi kertas tersebut, maka slot parkir tersebut dianggap kosong. Namun jika pada citra tidak terdapat lingkaran berwarna hijau, maka slot tersebut sedang terisi karena lingkaran tersebut tertutup oleh mobil yang sedang parkir. Pada penelitian tersebut, terdapat kendala yaitu sulitnya menempatkan kamera di posisi yang tepat. Kamera harus berada tepat di tengah area parkir dengan ketinggian yang cukup. Hal ini sulit untuk diimplementasikan pada tempat parkir dalam ruangan (indoor) karena keterbatasan langitlangit yang ada di tempat parkir. Selain itu, kondisi pencahayaan dan cuaca turut mempengaruhi citra tangkapan kamera, akibatnya warna kertas yang seharusnya hijau tertangkap sebagai warna lain pada kamera.

Pendekatan lain dilakukan oleh Nugraha untuk mengatasi permasalahan tersebut dengan membangun sebuah sistem parkir cerdas menggunakan penanda (marker) khusus yang dimonitor oleh kamera pengawas [17]. Marker tersebut ditempatkan pada masing-masing slot parkir, tepatnya di lantai yang akan ditempati oleh sebuah mobil. Setiap marker memiliki motif yang berbedabeda, di mana setiap motif mereferensikan sebuah slot tempat parkir. Apabila kamera pengawas mendeteksi adanya motif marker dalam rekaman, maka slot tempat parkir tersebut sedang tidak ditempati, karena marker tersebut tidak tertutupi oleh mobil. Penelitian tersebut menghasilkan nilai akurasi maksimal $91.94 \%$ dalam mendeteksi ketersediaan area parkir. Kendala yang dialami penelitian tersebut adalah sulitnya untuk menemukan motif marker yang tepat. Apabila motif marker terlalu sederhana, maka terdapat kemungkinan motif tersebut akan muncul pada obyek lain di luar marker. Namun jika motif tersebut terlalu rumit, maka akan sulit untuk dikenali oleh kamera pengawas. Selain itu kondisi cahaya juga turut mempengaruhi citra hasil tangkapan kamera pengawas. Pada beberapa sudut cahaya, motif di dalam marker tidak dapat terbaca akibat adanya pantulan cahaya yang cukup terang.

Penelitian lain mengenai sistem parkir cerdas dilakukan oleh Kommey, Addo, dan Agbemenu dengan menggunakan metode deteksi tepi Canny [18]. Sistem parkir cerdas tersebut dibangun dengan memanfaatkan kamera pengawas yang dipasang pada sebuah tiang yang cukup tinggi, sehingga kamera dapat menangkap seluruh area tempat parkir. Citra hasil tangkapan kamera diolah dengan menggunakan deteksi tepi Canny untuk mendeteksi garis-garis pada area tempat parkir, kemudian dilanjutkan dengan kombinasi metode dilasi untuk menentukan area parkir yang kosong dan yang terisi. Kekurangan dari sistem tersebut adalah terlalu bergantung pada garis pembatas parkir yang ada di sepanjang area parkir. Hal ini mengakibatkan kendala dalam mengarahkan kamera agar dapat mengambil citra dengan sudut yang tepat, sehingga seluruh garis parkir yang ada dapat tertangkap dengan baik Selain itu, apabila terdapat sebuah slot kosong yang diapit oleh mobil yang sedang terparkir di kedua sisinya, maka 
slot tersebut akan ikut terisi oleh metode dilasi. Akibatnya, slot yang kosong tersebut akan dianggap oleh sistem sedang terisi sebuah mobil.

Berdasarkan penelitian-penelitian sejenis yang telah dilakukan sebelumnya, maka penelitian terkait sistem pencarian area parkir dilakukan dengan mempertimbangkan kekurangan dari penelitian-penelitian tersebut, seperti kondisi pencahayaan yang tidak menentu serta ketergantungan terhadap objek tertentu yang terdapat di area parkir (contohnya garis pembatas parkir). Melalui penelitian ini, sebuah sistem parkir cerdas dibangun tanpa memerlukan biaya besar untuk proses implementasinya, namun sistem tersebut diharapkan tetap dapat memberikan performa yang baik. Untuk menghemat biaya implementasi, sistem yang dibangun tidak menggunakan sensor khusus untuk mendeteksi keberadaan objek, melainkan dengan memanfaatkan kamera pengawas yang biasanya telah tersedia di area parkir untuk mendeteksi ketersediaan lahan parkir. Agar proses implementasi sistem parkir cerdas dapat dilakukan dengan mudah, maka pada penelitian ini mencoba untuk menerapkan algoritma background substraction yang lebih fleksibel dibandingkan dengan metode lain pada penelitian-penelitian sebelumnya. Berdasarkan penelitian yang dilakukan oleh Nugraha dan Saputra, metode background substraction dapat digunakan untuk melihat perbedaan kondisi dua buah citra [8]. Metode background substraction bekerja dengan cara membandingkan dua buah citra hasil tangkapan pengawas, sehingga tidak dibutuhkan adanya instalasi atau pemasangan perangkat lain seperti sensor atau marker. Dengan demikian, metode background substraction dapat lebih mudah diimplementasikan untuk sistem parkir cerdas menggunakan kamera pengawas karena cukup menambahkan algoritma yang dapat mengolah hasil rekaman dari kamera pengawas.

\section{LANDASAN TEORI}

Penelitian ini menerapkan beberapa konsep dan metode untuk membangun sistem parkir cerdas dengan memanfaatkan kamera pengawas, yaitu metode background substraction untuk menganalisis citra area parkir, serta konsep service-oriented architecture untuk membangun sistem secara keseluruhan hingga dapat digunakan oleh pengguna dalam bentuk perangkat lunak pada perangkat ponsel cerdas (smartphone).

\section{A. Pengolahan Citra Digital}

Pengolahan citra digital merupakan salah satu cabang dari bidang ilmu komputer yang mempelajari tentang metode dan algoritma dalam mengolah citra dengan format digital. Citra digital dapat diperoleh dari perangkat digital seperti kamera digital, alat pemindai (scanner), atau menggunakan perangkat lunak pengolah citra pada komputer. Citra digital diolah lebih lanjut menggunakan metode atau algoritma tertentu dengan tujuan untuk mendapatkan informasi atau fitur yang tidak terlihat sebelumnya, salah satu contohnya adalah untuk mendapatkan informasi motif yang terdapat pada citra kain batik [19] atau untuk menentukan busuk atau tidaknya buah jeruk yang direkam dalam bentuk citra [20]. Selain untuk mengolah citra menjadi sebuah informasi, pengolahan citra digital juga dapat digunakan untuk mengubah sebuah citra menjadi citra lain yang dianggap lebih baik, atau mengubah sebuah informasi ke dalam bentuk citra yang dapat merepresentasikan informasi tersebut.

\section{B. Background Substraction}

Background substraction merupakan salah satu metode pengolahan citra digital yang bertujuan untuk memisahkan latar belakang (background) dengan latar depan (foreground) [21].

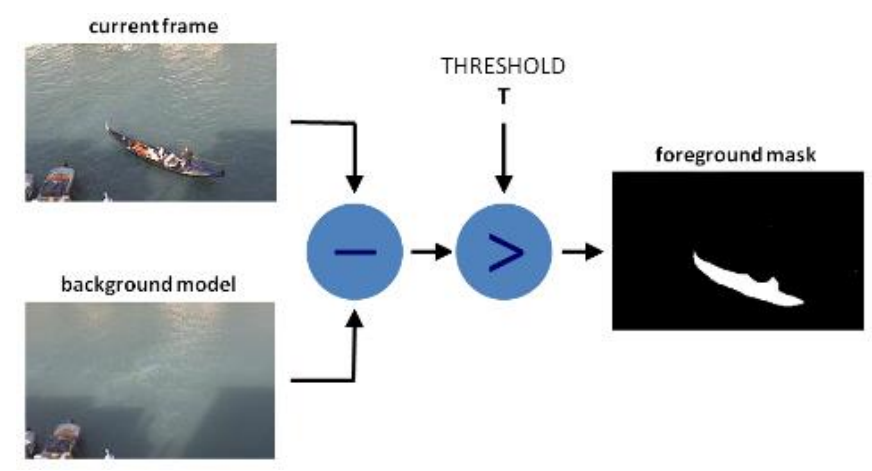

Gambar 1. Langkah-langkah metode background substraction [22].

Proses pemisahan ini dilakukan dengan cara mencari selisih antara dua citra (background dan foreground), kemudian memindahkan nilai selisih yang berada di atas nilai ambang (threshold) ke dalam sebuah matriks seperti ditunjukkan pada gambar 1 . Perbedaan nilai antara kedua citra ditunjukkan menggunakan warna putih jika citra menggunakan latar belakang hitam, demikian pula sebaliknya. Rumus perhitungan metode background substraction ditunjukkan pada rumus 1 .

$D(x, y)=\left\{\begin{array}{l}1 \text { if } F(x, y)-B(x, y)>T \\ 0 \text { if } F(x, y)-B(x, y) \leq T\end{array}\right.$

di mana:

$$
\begin{aligned}
& \mathrm{B}=\text { citra background } \\
& \mathrm{F}=\text { citra foreground } \\
& \mathrm{T}=\text { nilai ambang batas (threshold) }
\end{aligned}
$$


Pada penelitian ini, algoritma background substraction digunakan sebagai metode utama dalam menentukan kosong atau tidaknya sebuah slot tempat parkir. Citra background adalah citra saat kondisi tempat parkir dalam keadaan kosong, sedangkan citra foreground adalah citra tempat parkir terbaru. Apabila pada zona-zona di dalamnya ditemukan selisih yang melebihi nilai ambang, maka dapat disimpulkan bahwa zona tempat parkir tersebut telah terisi.

\section{Service-Oriented Architecture}

Service-oriented architecture merupakan sebuah konsep pembangunan perangkat lunak dengan melibatkan dua buah sistem, yaitu server dan client [23]. Server berperan sebagai penyedia layanan serta pusat basis data yang menyimpan seluruh informasi terkait dengan jalannya sistem. Sedangkan client berperan sebagai pengguna layanan terkait dengan data yang dimiliki oleh server. Apabila client telah berhasil mengambil data dari server, maka tugas berikutnya adalah untuk data tersebut kepada pengguna. Gambaran cara kerja arsitektur tersebut ditunjukkan pada gambar 2. Dengan menggunakan mekanisme ini, maka seluruh proses logika dan basis data penyimpanan (service) akan ditangani oleh server tanpa perlu terikat dengan client. Tugas dari client adalah menangani bagian antarmuka yang digunakan oleh pengguna untuk berinteraksi. Kelebihan dari penggunaan service-oriented architecture adalah dapat memudahkan pengembang perangkat lunak untuk membangun maupun memodifikasi aplikasi client pada jenis platform apapun tanpa perlu mengubah proses logika yang telah ada sebelumnya.

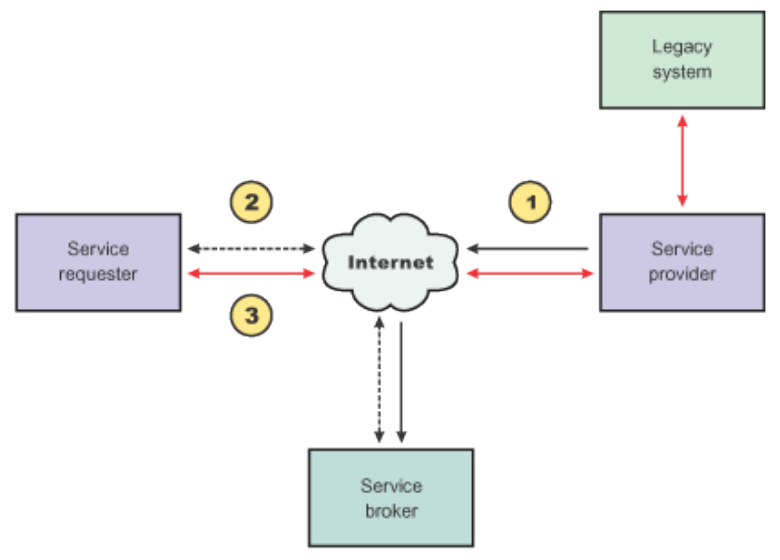

Gambar 2. Langkah kerja service-oriented architecture [24].

Pada penelitian ini, server merupakan komputer pusat dengan tugas utama untuk mengambil dan mengolah citra yang diperoleh dari kamera pengawas. Dari citra yang telah dianalisis, akan didapatkan daftar rincian mengenai ketersediaan slot parkir terbaru kemudian menyimpannya ke dalam basis data. Sedangkan client adalah aplikasi pada perangkat ponsel cerdas (smartphone) yang memiliki akses untuk membaca informasi ketersediaan area parkir dari server. Pengguna kendaraan yang hendak mengetahui informasi mengenai area parkir dapat membuka aplikasi tersebut, kemudian melihat daftar slot tempat parkir yang tersedia. Komunikasi antara client dan server dilakukan melalui perantara jaringan internet, sehingga apabila koneksi internet milik salah satu pihak mengalami kendala, maka komunikasi akan turut terhambat.

\section{METODE PENELITIAN}

Penelitian ini dilakukan dalam beberapa tahapan yang terdiri dari pengumpulan data, pembangunan sistem, pengujian sistem, dan evaluasi sistem. Sebagai objek penelitian, penelitian ini menggunakan area parkir bawah tanah (basement) khusus untuk kendaraan beroda empat di area Universitas Kristen Duta Wacana. Di area ini telah terdapat kamera pengawas yang tersebar pada beberapa titik, sehingga tidak diperlukan adanya instalasi perangkat baru untuk melaksanakan penelitian. Jenis kamera yang digunakan pada penelitian ini adalah Xiaomi Security Camera 360. Seluruh kamera tersebut dipasang pada langit-langit atau tembok bagian atas di area tempat parkir basement. Akses rekaman pada kamera pengawas untuk keperluan penelitian diperoleh melalui izin dari bagian keamanan.

\section{A. Pengumpulan Data}

Tahap pengumpulan data dilakukan dengan cara mengambil beberapa contoh citra dari seluruh kamera pengawas yang terpasang di beberapa titik pada area parkir. Terdapat dua kategori citra yang dikumpulkan, yaitu citra saat kondisi area parkir sedang kosong sepenuhnya dan citra saat area parkir terisi sebagian maupun penuh. Citracitra tersebut dipelajari terlebih dahulu untuk mempelajari karakteristik masing-masing citra yang diperoleh dari kamera pengawas yang berbeda. Citra dari setiap kamera memiliki sudut pandang yang berbeda, sehingga jumlah dan posisi kendaraan yang dapat terekam pada citra juga memiliki perbedaan. Contoh citra kamera pengawas ditunjukkan pada gambar 3. Selain itu, citra juga diambil secara acak dari pukul 7.00 sampai dengan pukul 17.00, dengan pertimbangan bahwa di luar rentang waktu tersebut sangat sedikit mobil yang menempati area parkir, sehingga sistem parkir tidak diperlukan. Pengambilan sample secara acak berdasarkan waktu memiliki tujuan agar terdapat variasi kondisi pencahayaan matahari yang tertangkap oleh citra. Selain itu, pukul 15.00 lampu berjenis neon yang terpasang di sepanjang area parkir mulai dinyalakan, hal ini juga turut menjadi variasi dari sample yang diambil. 


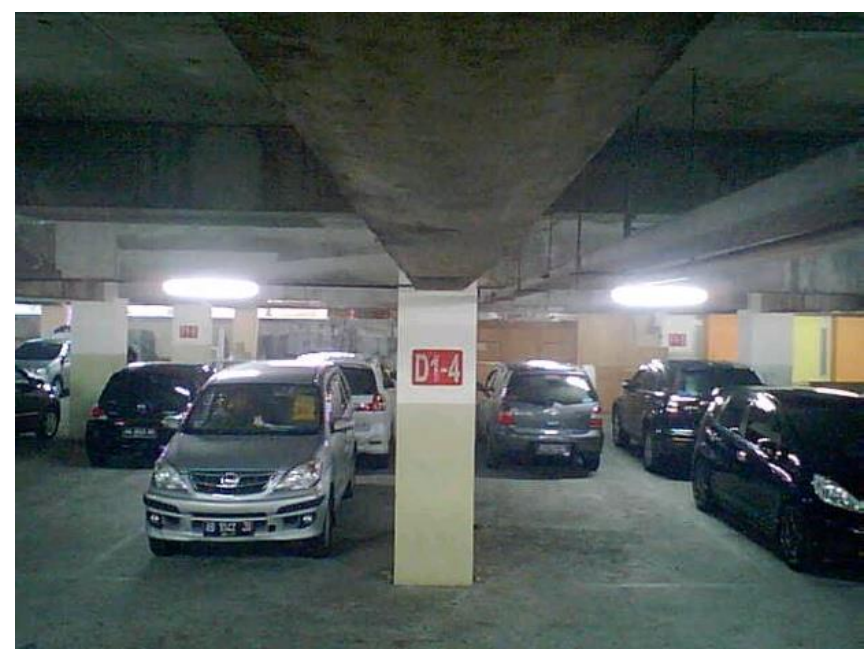

Gambar 3. Contoh citra kamera pengawas.

Sistem hanya akan menentukan ketersediaan tempat parkir dari barisan mobil yang paling dekat dengan kamera pengawas. Karena apabila barisan tersebut terisi mobil secara penuh, maka barisan di belakangnya akan tertutupi sehingga sistem tidak akan dapat menentukan ketersediaan tempat parkir pada barisan belakang.

\section{B. Pembangunan Sistem}

Pembangunan sistem diawali dengan perancangan mengenai arsitektur sistem secara keseluruhan. Pada penelitian ini, terdapat tiga komponen utama yang berperan dalam jalannya sistem, yaitu kamera pengawas, komputer server, dan aplikasi smartphone. Gambaran mengenai arsitektur sistem dapat dilihat pada gambar 4. Seluruh kamera pengawas terhubung secara langsung dengan server melalui jaringan lokal, sehingga server dapat membaca citra dari kamera pengawas dengan mudah. Sedangkan client (aplikasi smartphone) terhubung dengan server melalui perantara jaringan internet, sehingga aplikasi dapat diakses di manapun pengguna berada selama terhubung dengan jaringan internet.

Pada komputer server, dibangun program menggunakan bahasa pemrograman $\mathrm{C} \#$ untuk mengambil dan menganalisis citra kamera pengawas, kemudian menyimpan informasi tersebut ke dalam basis data. Sedangkan pada aplikasi smartphone, dibangun program untuk perangkat Android dengan menggunakan bahasa pemrograman Java dan perangkat lunak Android Studio. Aplikasi ini berfungsi agar pengguna kendaraan dapat melihat informasi ketersediaan tempat parkir.

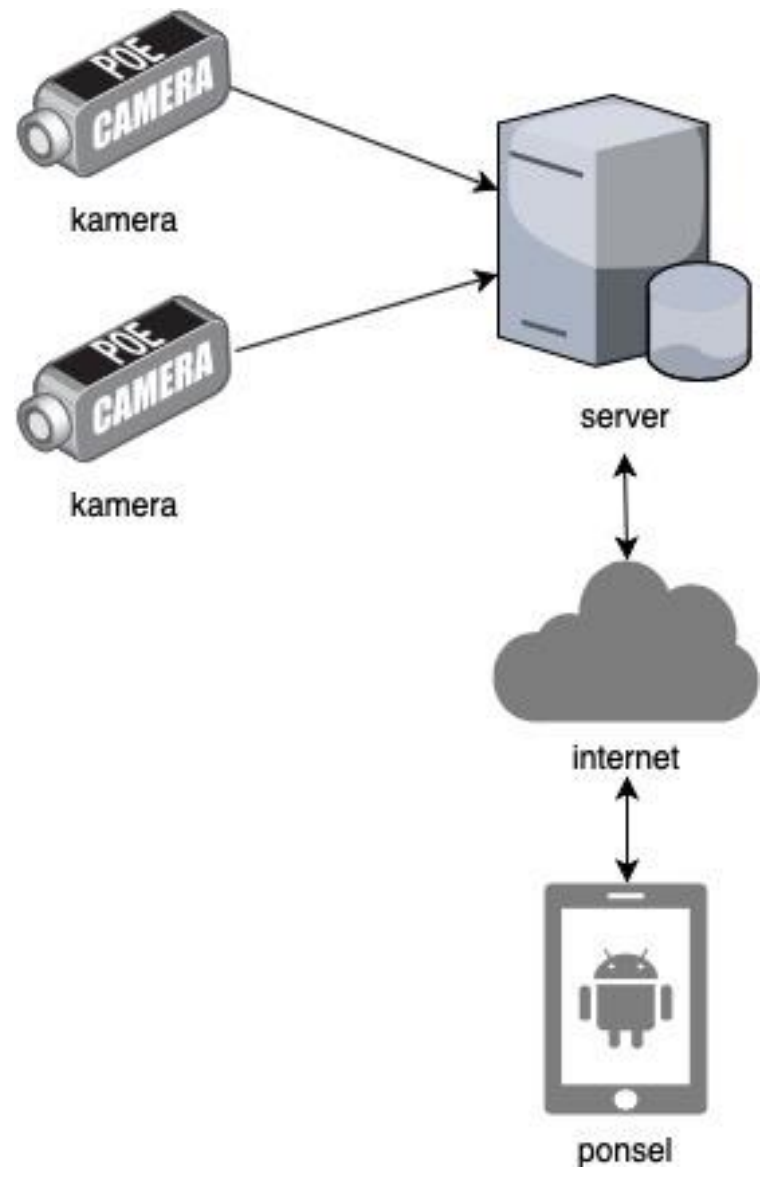

Gambar 4. Arsitektur sistem parkir cerdas

\section{Pengujian Sistem}

Pada komputer server, pengujian dilakukan dengan menggunakan sample data uji sebanyak 65 buah citra yang diambil secara acak dari 10 lokasi kamera pengawas yang berbeda. Citra-citra tersebut memiliki karakteristik yang berbeda dari sisi sudut pengambilan citra, pencahayaan (pagi, siang, sore, malam) serta komposisi kendaraan yang sedang parkir di dalamnya (jumlah dan tipe mobil). Citra yang diambil hanya citra dengan kondisi minimal terdapat satu buah mobil yang sedang terparkir dan mobil yang sedang terparkir dapat terlihat jelas. Apabila mobil yang sedang terparkir tertutup oleh mobil lain yang sedang berjalan atau tertutup objek lain sehingga tidak tertangkap oleh kamera pengawas, maka citra tersebut tidak diikutsertakan dalam sample pengujian. Tingkat akurasi dihitung dengan menggunakan confusion matrix dengan cara membandingkan jumlah slot parkir hasil pengenalan sistem dengan jumlah slot parkir aktual. 


\section{Evaluasi Sistem}

Evaluasi dilakukan dengan menganalisis hasil pengujian yang telah dilakukan pada tahap sebelumnya. Proses evaluasi bertujuan untuk menarik kesimpulan berkaitan dengan kelebihan dan kekurangan dari sistem parkir cerdas yang telah dibangun. Kendala maupun hambatan yang ditemukan selama proses penelitian berlangsung dapat digunakan sebagai pembelajaran atau catatan untuk penelitian sejenis berikutnya.

\section{HASIL DAN ANALISIS}

Sistem parkir cerdas yang telah dibangun mampu membaca dan mengolah citra yang diambil dari kamera pengawas. Mula-mula sistem akan mengambil citra asli dari kamera pengawas seperti ditunjukkan pada gambar 5 .

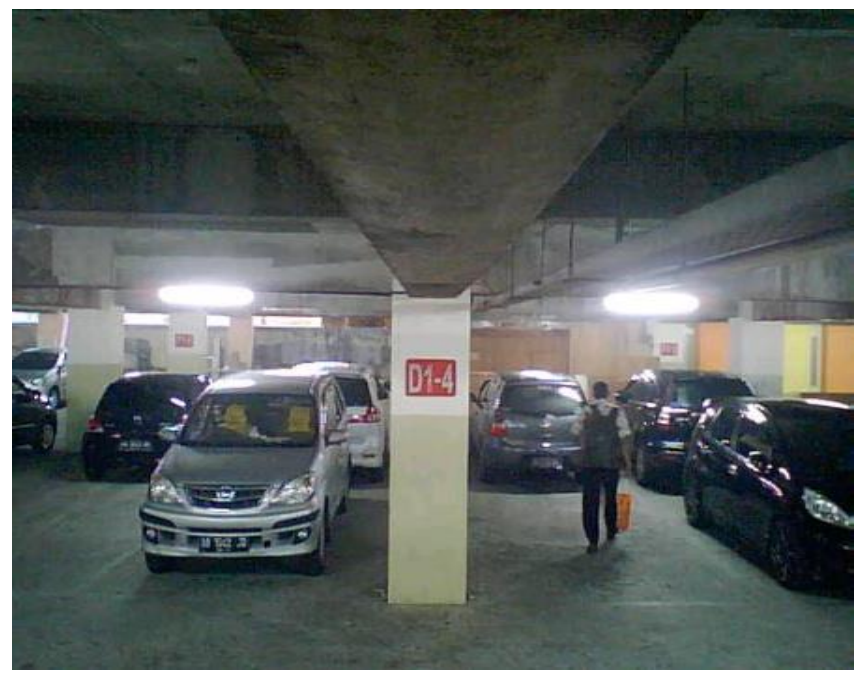

Gambar 5. Contoh citra asli dari kamera pengawas di titik D1-4

Kemudian sistem akan mengambil citra background yang sesuai dengan citra gambar 5 berdasarkan posisi kamera pengawas, dalam contoh tersebut menggunakan kamera pengawas area D1-4. Citra background untuk gambar 5 ditunjukkan pada gambar 6 .

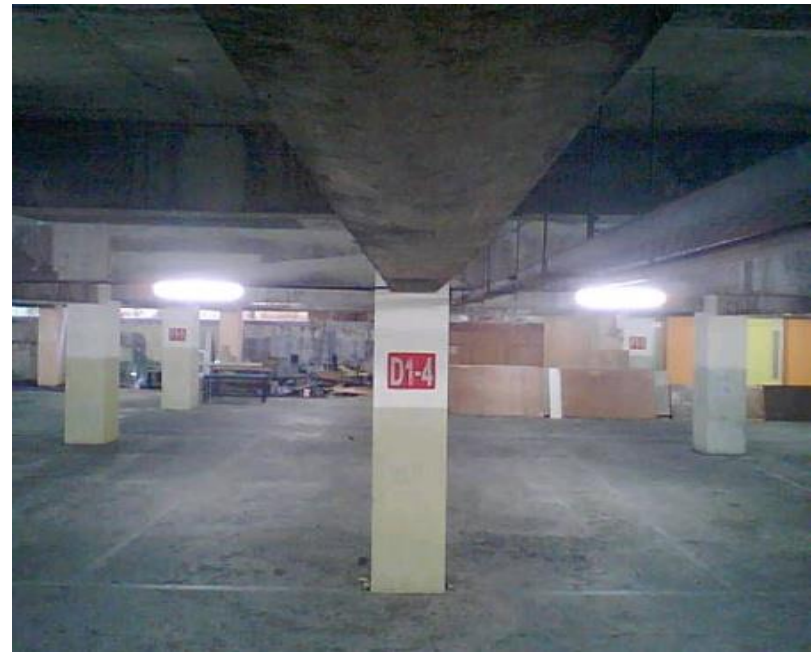

Gambar 6. Citra background D1-4

Kedua citra tersebut akan diolah menjadi citra aras keabuan (grayscale) seperti ditunjukkan pada gambar 7 . Kemudian kedua citra tersebut diolah menggunakan metode background substraction, hasilnya ditunjukkan pada gambar 8 .

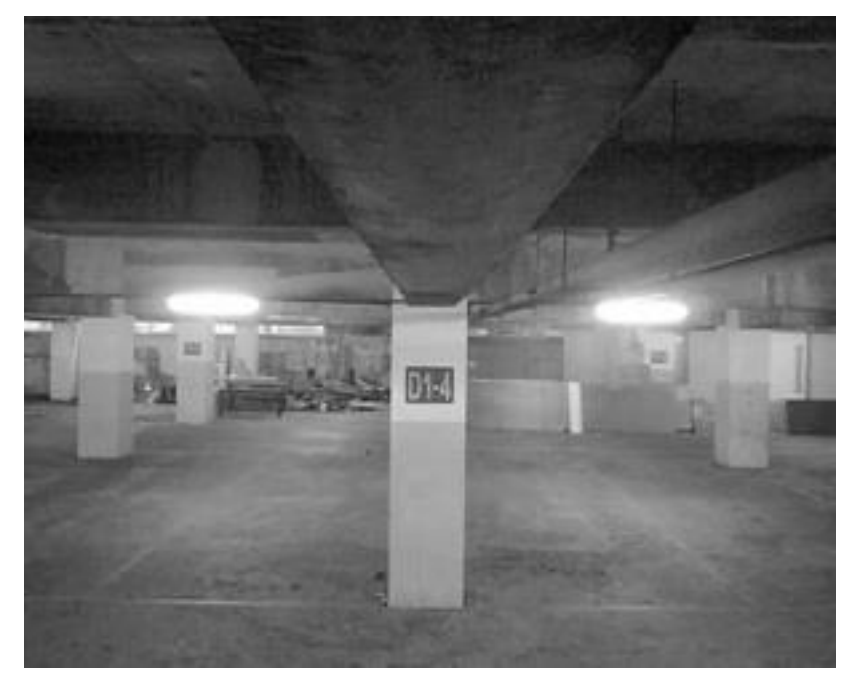

(a) 


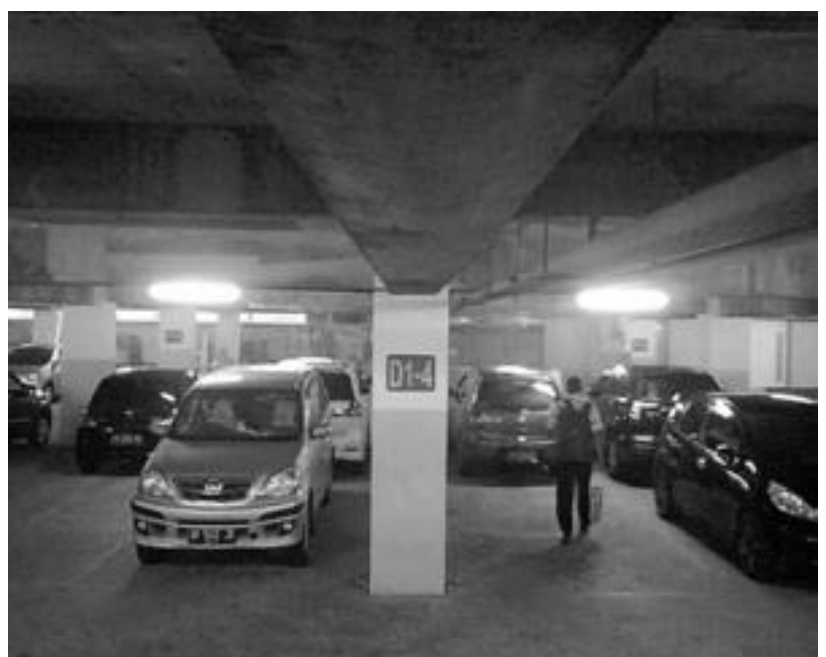

(b)

Gambar 7. Citra grayscale background (a) dan foreground (b)

Pada citra hasil background substraction, piksel berwarna putih merupakan piksel yang memiliki perbedaan antara citra background dengan citra foreground. Apabila pada zona yang telah ditentukan sebelumnya terdapat lebih dari separuh area berwarna putih, maka slot tempat parkir tersebut dinyatakan terisi.

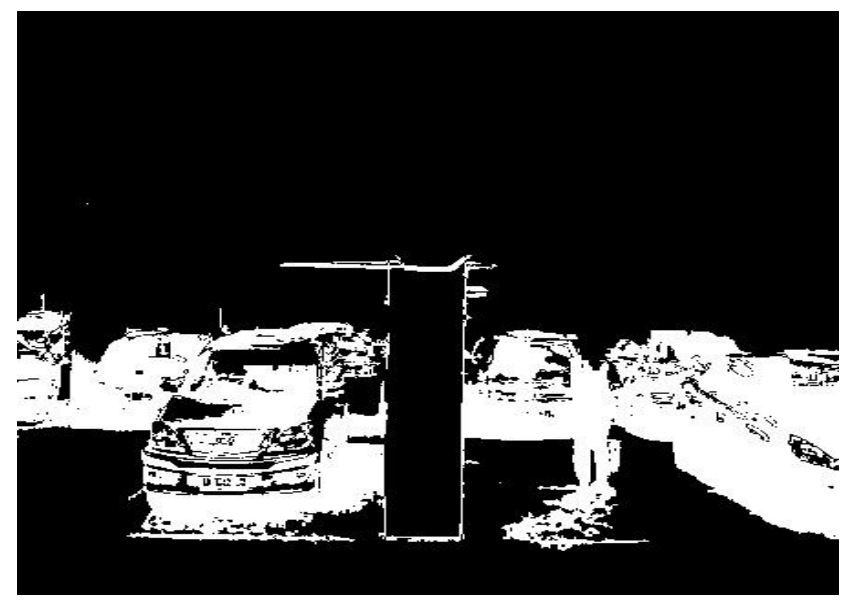

Gambar 8. Citra hasil background substraction

Pada gambar 9 dapat terlihat bahwa hanya dua dari empat zona yang memiliki piksel berwarna putih lebih dari separuh area (ditandai dengan warna hijau), sehingga kedua zona tersebut dinyatakan terisi. Sedangkan zona yang diberi warna merah dinyatakan kosong, sehingga dapat digunakan oleh pengguna kendaraan yang hendak memarkirkan kendaraannya.

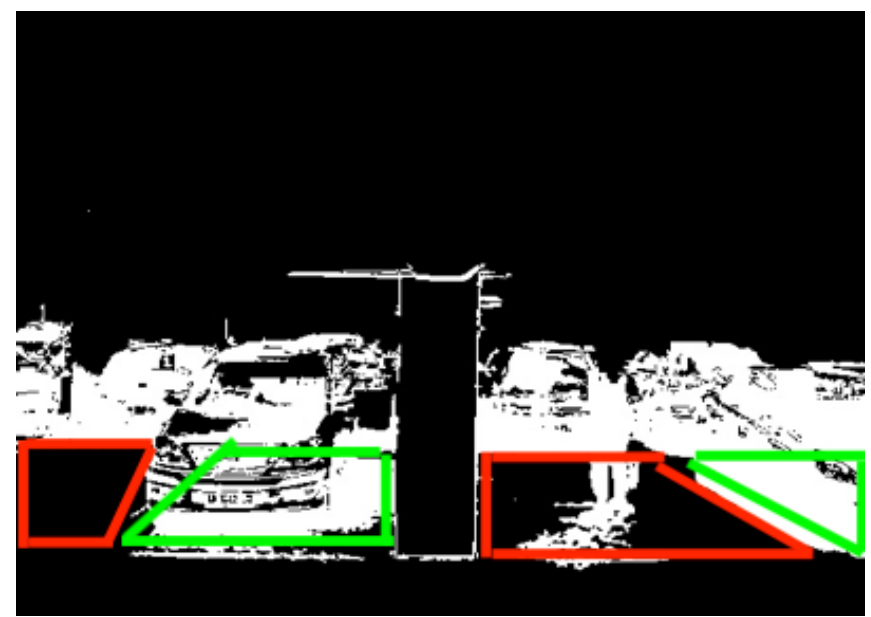

Gambar 9. Citra hasil pengenalan sistem

Sistem parkir cerdas diuji untuk mengukur tingkat akurasi ketepatan dalam menghitung ketersediaan tempat parkir. Hasil pengujian akurasi ditunjukkan pada Tabel I. Nilai True positif (+) menunjukkan jumlah slot parkir yang terisi mobil pada citra, True negatif (-) menunjukkan jumlah slot mobil yang kosong pada citra, False positif (+) menunjukkan jumlah slot parkir yang kosong pada citra namun dianggap tidak kosong oleh sistem, dan False negatif (-) menunjukkan jumlah slot parkir yang terisi mobil pada citra namun dianggap kosong oleh sistem. Nilai Total adalah jumlah total slot parkir yang mampu tertangkap oleh kamera. Nilai Persentase adalah jumlah nilai True (positif dan negatif) dibagi dengan jumlah nilai Total.

TABEL I

HASIL PENGUJIAN AKURASI Sistem

\begin{tabular}{|c|c|c|c|c|c|c|}
\hline \multirow{2}{*}{} & \multicolumn{2}{|c|}{ True } & \multicolumn{2}{c|}{ False } & \multirow{2}{*}{ Total } & \multirow{2}{*}{ Persentase } \\
\cline { 2 - 5 }$(+)$ & $(-)$ & $(+)$ & $(-)$ & & \\
\hline 1 & 2 & 2 & 0 & 0 & 4 & $100 \%$ \\
\hline 2 & 1 & 3 & 0 & 0 & 4 & $100 \%$ \\
\hline 3 & 0 & 4 & 0 & 0 & 4 & $100 \%$ \\
\hline 4 & 2 & 2 & 0 & 0 & 4 & $100 \%$ \\
\hline 5 & 0 & 4 & 0 & 0 & 4 & $100 \%$ \\
\hline 6 & 3 & 1 & 0 & 0 & 4 & $100 \%$ \\
\hline 7 & 4 & 0 & 0 & 0 & 4 & $100 \%$ \\
\hline 8 & 4 & 0 & 0 & 0 & 4 & $100 \%$ \\
\hline 9 & 0 & 4 & 0 & 0 & 4 & $100 \%$ \\
\hline 10 & 0 & 4 & 0 & 0 & 4 & $100 \%$ \\
\hline 11 & 0 & 4 & 0 & 0 & 4 & $100 \%$ \\
\hline 12 & 2 & 1 & 0 & 1 & 4 & $75 \%$ \\
\hline 13 & 2 & 2 & 0 & 0 & 4 & $100 \%$ \\
\hline 14 & 1 & 1 & 0 & 0 & 2 & $100 \%$ \\
\hline
\end{tabular}




\begin{tabular}{|c|c|c|c|c|c|c|}
\hline & \multicolumn{2}{|c|}{ True } & \multicolumn{2}{|c|}{ False } & \multirow{2}{*}{ Total } & \multirow{2}{*}{ Persentase } \\
\hline & $(+)$ & $(-)$ & $(+)$ & $(-)$ & & \\
\hline 15 & 1 & 1 & 0 & 0 & 2 & $100 \%$ \\
\hline 16 & 1 & 1 & 0 & 0 & 2 & $100 \%$ \\
\hline 17 & 2 & 0 & 0 & 0 & 2 & $100 \%$ \\
\hline 18 & 2 & 2 & 0 & 0 & 4 & $100 \%$ \\
\hline 19 & 0 & 3 & 1 & 0 & 4 & $75 \%$ \\
\hline 20 & 0 & 3 & 1 & 0 & 4 & $75 \%$ \\
\hline 21 & 1 & 3 & 0 & 0 & 4 & $100 \%$ \\
\hline 22 & 1 & 3 & 0 & 0 & 4 & $100 \%$ \\
\hline 23 & 1 & 3 & 0 & 0 & 4 & $100 \%$ \\
\hline 24 & 2 & 2 & 0 & 0 & 4 & $100 \%$ \\
\hline 25 & 1 & 2 & 0 & 1 & 4 & $75 \%$ \\
\hline 26 & 2 & 2 & 0 & 0 & 4 & $100 \%$ \\
\hline 27 & 0 & 3 & 0 & 0 & 3 & $100 \%$ \\
\hline 28 & 1 & 2 & 0 & 0 & 3 & $100 \%$ \\
\hline 29 & 2 & 1 & 0 & 0 & 3 & $100 \%$ \\
\hline 30 & 2 & 1 & 0 & 0 & 3 & $100 \%$ \\
\hline 31 & 2 & 0 & 0 & 0 & 2 & $100 \%$ \\
\hline 32 & 1 & 1 & 0 & 0 & 2 & $100 \%$ \\
\hline 33 & 1 & 0 & 1 & 0 & 2 & $50 \%$ \\
\hline 34 & 1 & 1 & 0 & 0 & 2 & $100 \%$ \\
\hline 35 & 2 & 0 & 0 & 0 & 2 & $100 \%$ \\
\hline 36 & 2 & 0 & 0 & 0 & 2 & $100 \%$ \\
\hline 37 & 0 & 3 & 0 & 0 & 3 & $100 \%$ \\
\hline 38 & 0 & 3 & 0 & 0 & 3 & $100 \%$ \\
\hline 39 & 0 & 3 & 0 & 0 & 3 & $100 \%$ \\
\hline 40 & 0 & 3 & 0 & 0 & 3 & $100 \%$ \\
\hline 41 & 1 & 2 & 0 & 0 & 3 & $100 \%$ \\
\hline 42 & 2 & 1 & 0 & 0 & 3 & $100 \%$ \\
\hline 43 & 3 & 0 & 0 & 0 & 3 & $100 \%$ \\
\hline 44 & 3 & 0 & 0 & 0 & 3 & $100 \%$ \\
\hline 45 & 4 & 0 & 0 & 0 & 4 & $100 \%$ \\
\hline 46 & 3 & 1 & 0 & 0 & 4 & $100 \%$ \\
\hline 47 & 2 & 2 & 0 & 0 & 4 & $100 \%$ \\
\hline 48 & 1 & 2 & 1 & 0 & 4 & $75 \%$ \\
\hline 49 & 0 & 4 & 0 & 0 & 4 & $100 \%$ \\
\hline 50 & 0 & 4 & 0 & 0 & 4 & $100 \%$ \\
\hline 51 & 0 & 3 & 0 & 0 & 3 & $100 \%$ \\
\hline 52 & 1 & 1 & 1 & 0 & 3 & $67 \%$ \\
\hline 53 & 1 & 1 & 1 & 0 & 3 & $67 \%$ \\
\hline
\end{tabular}

\begin{tabular}{|c|c|c|c|c|c|c|}
\hline & \multicolumn{2}{|c|}{ True } & \multicolumn{2}{|c|}{ False } & \multirow{2}{*}{ Total } & \multirow{2}{*}{ Persentase } \\
\hline & $(+)$ & $(-)$ & $(+)$ & $(-)$ & & \\
\hline 54 & 2 & 1 & 0 & 0 & 3 & $100 \%$ \\
\hline 55 & 2 & 1 & 0 & 0 & 3 & $100 \%$ \\
\hline 56 & 2 & 1 & 0 & 0 & 3 & $100 \%$ \\
\hline 57 & 3 & 0 & 0 & 0 & 3 & $100 \%$ \\
\hline 58 & 3 & 0 & 0 & 0 & 3 & $100 \%$ \\
\hline 59 & 0 & 2 & 0 & 0 & 2 & $100 \%$ \\
\hline 60 & 0 & 1 & 1 & 0 & 2 & $50 \%$ \\
\hline 61 & 0 & 2 & 0 & 0 & 2 & $100 \%$ \\
\hline 62 & 1 & 0 & 1 & 0 & 2 & $50 \%$ \\
\hline 63 & 1 & 0 & 0 & 1 & 2 & $50 \%$ \\
\hline 64 & 1 & 0 & 0 & 1 & 2 & $50 \%$ \\
\hline 65 & 1 & 0 & 0 & 1 & 2 & $50 \%$ \\
\hline \multicolumn{6}{|c|}{ Rata-rata } & $93.69 \%$ \\
\hline
\end{tabular}

Nilai rata-rata akurasi dari Tabel I adalah 93.69\%, hampir seluruh citra dapat dikenali dengan baik (100\%). Kondisi pencahayaan tidak berpengaruh terhadap kemampuan sistem dalam menentukan slot parkir yang kosong maupun yang terisi, karena seluruh citra masih dianggap memiliki kondisi pencahayaan yang cukup jelas. Sebagian data yang tidak bernilai akurasi $100 \%$ memiliki nilai pada kolom false positif seperti data pada nomor 19 , 20, 33, 48, 52, 53, 60, dan 62. Hal tersebut dikarenakan pada slot parkir yang kosong terdapat objek selain mobil pada slot tersebut yang tidak ada pada citra background, misalnya orang yang sedang berjalan di atas sebuah slot parkir. Sedangkan sebagian data yang lain memiliki nilai false negatif seperti pada data nomor 12, 25, 63, 64, dan 65 Hal tersebut dikarenakan warna mobil yang sedang parkir sama seperti warna pada citra background yaitu abu-abu. Akibatnya sistem menilai bahwa slot tersebut kosong karena tidak ditemukan adanya selisih nilai piksel antara citra foreground dengan background, namun pada kenyataannya slot tersebut telah terisi mobil seperti ditunjukkan pada gambar 10. Pada gambar 10c, seharusnya seluruh piksel berwarna putih karena seluruh zona citra background (gambar 10a) tertutup oleh mobil secara penuh (gambar 10b). Namun pada gambar 10c hanya sebagian piksel yang memiliki warna putih, sebagian sisanya memiliki warna hitam seolah tidak terdapat objek pada gambar tersebut. 


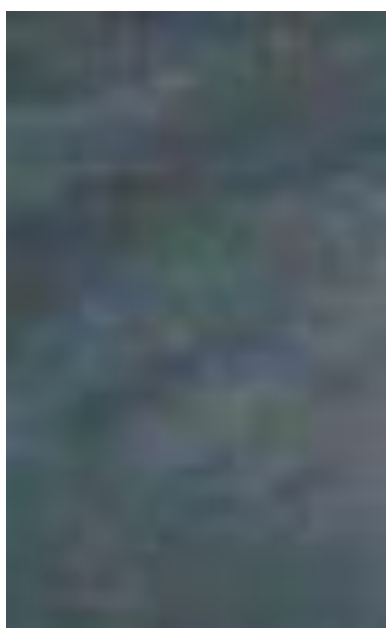

(a)

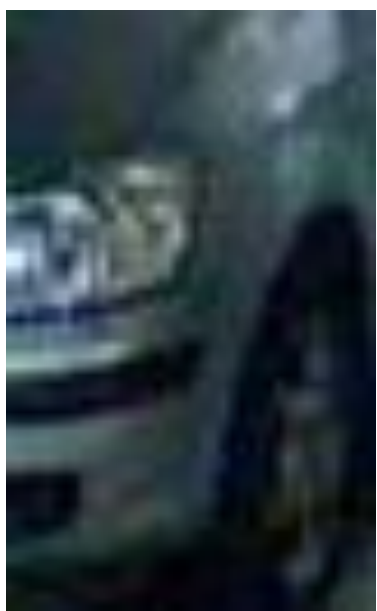

(b)

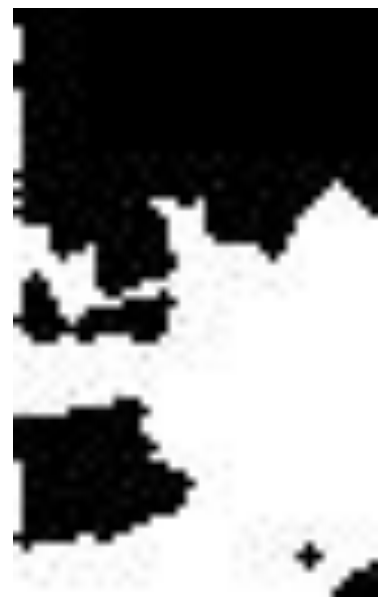

(c)

Gambar 10. Kesalahan pengenalan (c) pada sistem karena warna mobil (b) sama dengan warna background (a)

Data lokasi ketersediaan lokasi tempat parkir yang tersimpan pada server dapat diakses melalui perantara
Application Programming Interface (API). Melalui API tersebut, dapat dibangun aplikasi-aplikasi pihak ketiga untuk menampilkan informasi ketersediaan tempat parkir. Contoh tampilan aplikasi smartphone berbasis Android yang dibangun menggunakan data tersebut ditunjukkan pada gambar 11. Pada aplikasi tersebut, slot berwarna biru memiliki arti kosong sehingga dapat digunakan, sedangkan slot berwarna merah memiliki arti telah terisi kendaraan. Slot berwarna abu-abu merupakan slot yang tidak dapat digunakan untuk parkir karena adanya objek permanen di lokasi tersebut.

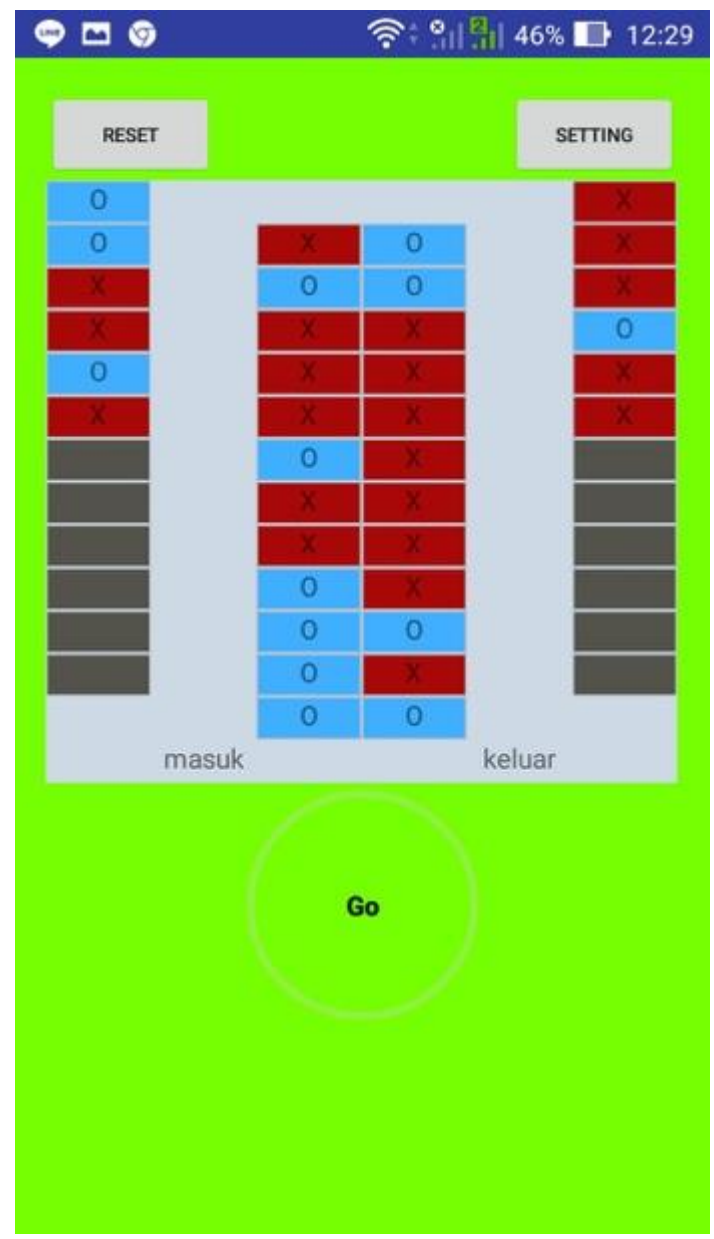

Gambar 11. Tampilan aplikasi smartphone

\section{KESIMPULAN}

Sistem parkir cerdas dengan memanfaatkan kamera pengawas telah dibangun dan dapat berjalan dengan baik. Sistem mampu memberikan informasi ketersediaan area parkir kepada pengguna dengan tingkat akurasi $93.69 \%$. Kendala yang dihadapi sistem adalah ketika terdapat objek yang menempati sebuah slot parkir, maka objek tersebut akan dianggap sebagai mobil yang sedang terparkir, karena 
sistem yang dibangun tidak memiliki kemampuan untuk mengenali jenis objek tertangkap oleh citra. Hal tersebut dapat diatasi dengan menambahkan sebuah algoritma untuk mengenali objek yang terdapat pada citra. Kendala lain adalah ketika terdapat mobil yang memiliki warna serupa dengan warna latar, sehingga sistem akan sulit mengenali mobil tersebut. Untuk mengatasi hal tersebut diperlukan metode pra-proses lain yang mengolah aspek lain selain warna pada citra, misalnya seperti tekstur, bentuk, atau kontur pada citra.

\section{UCAPAN TERIMA KASIH}

Ucapan terima kasih disampaikan kepada saudara Billy Fanino Bagyo sebagai asisten peneliti yang telah banyak memberikan kontribusi selama proses penelitian berlangsung.

\section{DAFTAR PUSTAKA}

[1] (2018) Perkembangan jumlah kendaraan bermotor menurut jenis, 1949-2018, Badan Pusat Statistik. [Online]. Tersedia: https://www.bps.go.id/linkTableDinamis/view/id/1133.

[2] B. Mishra, A. Verma, A. Gupta \& S. Singh, "Smart parking system," International Research Journal of Engineering and Technology (IRJET), vol. 5, no. 4, pp. 639-641, 2018.

[3] G. Yan, W. Yang, D. B. Rawat \& S. Olariu, "Smart parking: a secure and intelligent parking system," IEEE Intelligent Transportation Systems Magazine, vol. 3, no. 1, pp. 18-30, 2011.

[4] K. A. Nugraha, "The effectiveness of peripheral interaction concept for mobile phone usage while driving," International Conference on Information and Communications Technology (ICOIACT), 2018, pp. 701-704.

[5] G. Revathi \& V. R. S. Dhulipala, "Smart parking systems and sensors: a survey," International Conference on Computing, Communication and Applications (ICCCA), 2012, pp. 1-5.

[6] P. Sheelarani, S. P. Anand, S. Shamili \& K. Sruthi, "Effective car parking reservation system based on internet of things technologies," World Conference on Futuristic Trends in Research and Innovation for Social Welfare (Startup Conclave), 2016, pp. 1-

[7] T. Kiliç \& T. Tuncer, "Smart city application: Android based smart parking system," International Artificial Intelligence and Dato Processing Symposium (IDAP), 2017, pp. 1-4.

[8] K. A. Nugraha \& L. K. P. Saputra, "Pemanfaatan raspberry pi untuk sistem penghitung mobil otomatis pada kampus UKDW," Jurnal Teknik Informatika dan Sistem Informasi, vol. 3, no. 3, pp. 539-549, 2017.

[9] N. S. Sakpal \& M. Sabnis, "Adaptive background subtraction in images," International Conference On Advances in Communication and Computing Technology (ICACCT), 2018, pp. 439-444.
[10] T. Lin, H. Rivano \& F. L. Mouël, "A Survey of smart parking solutions," IEEE Transactions on Intelligent Transportation Systems, vol. 18, no. 12, pp. 3229 - 3253, 2017.

[11] A. O. Kotb, Y.-c. Shen \& Y. Huang, "Smart parking guidance, monitoring and reservations: a review," IEEE Intelligent Transportation Systems Magazine, vol. 9, no. 2, pp. 6 - 16, 2017.

[12] V. Paidi, H. Fleyeh, J. Håkansson \& R. G. Nyberg, "Smart parking sensors, technologies and applications for open parking lots: a review," IET Intelligent Transport Systems, vol. 12, no. 8, pp. 735 741, 2018.

[13] Basavaraju S. R, "Automatic smart parking system using internet of things (IOT)," International Journal of Scientific and Research Publications, vol. 5, no. 12, pp. 629-632, 2015.

[14] H. Chaudhary, P. Bansal \& B. Valarmathi, "Advanced CAR parking system using Arduino," 4th International Conference on Advanced Computing and Communication Systems (ICACCS), 2017, pp. $1-5$.

[15] J. Karthik, S. Kaur, N. R. M \& U. M. R. Ch, "Smart parking using image processing," International Journal for Research in Applied Science \& Engineering Technology (IJRASET), vol. 5, no. X, pp. 2283-2286, 2017.

[16] H. Al-Kharusi \& I. Al-Bahadly, "Intelligent parking managemen system based on image processing," World Journal of Engineering and Technology, vol. 2, no. 2, pp. 55-67, 2014.

[17] K. A. Nugraha, "Deteksi area parkir mobil berbasis marker menggunakan moment invariants dan K-NN," Jurnal Teknik Informatika dan Sistem Informasi (JuTISI), vol. 5, no. 1, pp. 112$121,2019$.

[18] B. Kommey, E. O. Addo \& A. S. Agbemenu, "A smart image processing-based system for parkingspace vacancy management," International Journal of Computer Applications, vol. 182, no. 5, pp. $1-6,2018$

[19] K. A. Nugraha, W. Hapsari \& N. A. Haryono, "Analisis tekstur pada citra motif batik untuk klasifikasi menggunakan K-NN," Informatika, vol. 10, no. 2, pp. 135-140, 2014.

[20] L. A. Sunjoyo, R. G. Santosa \& K. A. Nugraha, "Implementasi transformasi haar wavelet untuk deteksi citra jeruk nipis yang busuk," Informatika: Jurnal Teknologi Komputer dan Informatika, vol. 12, no. 2, pp. 165-173, 2016.

[21] V. D.R. \& N. Kumar, "Object tracking using background subtraction algorithm," International Journal of Engineering Research and General Science, vol. 3, no. 1, pp. 237-243, 2015.

[22] (2016) How to use background subtraction methods, OpenCV. [Online]. Tersedia: https://docs.opencv.org/3.2.0/d1/dc5/tutorial_background_subtracti on.html.

[23] Y. Zhang, Z. Jiang, X. Yu \& X. Song, "Mapping services to activities in service oriented architecture (SOA) design: simulation-driven optimizing method based on DODAF2.0," 2014 IEEE 8th International Symposium on Service Oriented System Engineering, 2014, pp. 156-157.

[24] (2019) Web services approach to a service-oriented architecture, IBM, [Online]. Tersedia: https://www.ibm.com/support/knowledgecenter/en/SSAW57_8.5.5 /com.ibm.websphere.nd.multiplatform.doc/ae/cwbs_soawbs.html. 